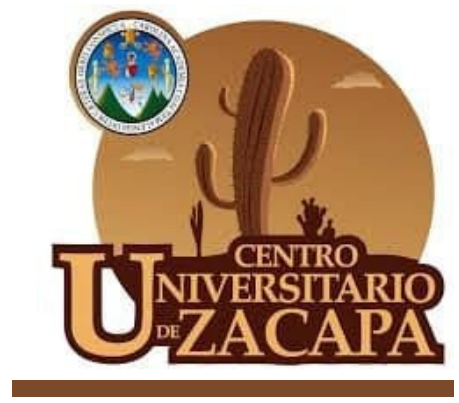

Recibido: 03/05/2021

Ensayo científico

Publicado: 24/06/2021

\title{
La estética de la música y la belleza de la trova
}

\author{
The aesthetics of music and the beauty of trova \\ Claudia Esmeralda Villela Cervantes \\ Universidad Mariano Gálvez de Guatemala \\ villeclaudiaesmeralda@gmail.com \\ https://orcid.org/0000-0002-8577-4376
}

\begin{abstract}
Referencia del ensayo
Villela-Cervantes, C. E. (2021). La estética de la música y la belleza de la trova. Revista Académica CUNZAZ. 4(2). 49-53. DOI: https://doi.org/10.46780/cunzac.v4i2.43.
\end{abstract}

\section{Resumen}

La estética de la música y la belleza de la trova, se vio reflejada en la actividad de disertación académico-musical que se realizó en el Doctorado en Investigación en Educación, el sábado 1 de mayo del año 2021; con el Cantor y Trovador Otto Mora, quien inició expresando que el arte integra la música como una manifestación que proporciona una experiencia estética que motiva la percepción individual, la creatividad y estimula los sentimientos, los pensamientos y las ideas. Gracias a los aspectos personales de tipo emocional, lo cual permite descubrir la estética de la obra. Entre los elementos estéticos musicales están la armonía y la emotividad, que están inmersos en la estética y las relaciones entre complejidad y estética, que conocen de diversidad, de transformaciones, de transiciones, de emergencia, de impredecibilidad y de autoorganización. Y el pensamiento sistémico, que nos plantea el concepto de propiedades emergentes de los sistemas como el calor, la sinergia y la buena vibra; aseguró Mora que la música es una propiedad emergente del sistema que la produce.

Palabras clave: estética de la música, trova

\begin{abstract}
The aesthetics of music and the beauty of the trova, was reflected in the academic-musical dissertation activity that was carried out in the Doctorate in Research in Education, on Saturday, May 1, 2021; with the Cantor and Troubadour Otto Mora, who begins by expressing that art integrates music as a manifestation that provides an aesthetic experience that motivates individual perception, creativity and stimulates feelings, thoughts and ideas. Thanks to the personal aspects of an emotional nature, which allows us to discover the aesthetics of the work. Among the aesthetic musical elements are harmony and emotionality, which are immersed in aesthetics and the relationships between complexity and aesthetics, which are aware of diversity, transformations, transitions, emergence, unpredictability and self-organization. And systemic thinking, which raises the concept of emergent properties of systems such as heat, synergy and good vibes; Mora assured that music is an emergent property of the system that produces it.
\end{abstract}

Keywords: aesthetics of music, trova 


\section{Contenido}

\section{Las circunstancias}

El sábado 1 de mayo del año 2021, se realizó la sesión de trabajo conjunta, correspondiente a diferentes cohortes del Doctorado en Investigación en Educación, para tres extensiones de la Universidad de San Carlos de Guatemala: (a) Centro Universitario de Zacapa (CUNZAC), ubicada en la cabecera departamental de Zacapa; (b) Centro Universitario de Occidente (CUNOC), con sede en la cabecera de Quetzaltenango y (c) Centro Universitario de Oriente (CUNO$\mathrm{RI}$ ), con sede en la cabecera de Chiquimula.

Como corresponde, dadas las circunstancias de la pandemia COVID-19, el evento se desarrolló de manera virtual, empleando la plataforma Zoom. Nos reunimos los doctorandos, el grupo doctoral y autoridades académicas que administran los programas; para disfrutar de una velada en formato de Disertación Académico-musical titulada "La Estética de la música y la belleza de la trova", la cual contó con la participación del trovador Otto Mora.

En la agenda académica que escribió la coordinadora Doctora Leticia Hurtado, se lee:

"Todo en el universo tiene un ritmo, todo baila" Maya Angelou, (activista y cantante). "Si no fuera físico, probablemente sería músico. A menudo pienso en música. Vivo mis sueños en música. Veo mi vida en términos musicales. No puedo decir si habría podido hacer alguna pieza creativa de importancia en la música, pero sí sé que lo que más alegría me da en la vida es mi violín" Albert Einstein.

\section{El cantautor trovador}

Otto Mora nació en Quetzaltenango en 1965. Es cantautor, intérprete de marimba, guitarrista, bajista y armonicista. Ha integrado y a veces fundado varios grupos de música latinoamericana, tal el caso de Caudal, Kenchas, Jazzúcar y su banda Antibajos. Ha compuesto cerca de 100 canciones. Musicaliza la poesía de escritores del istmo, sobresaliendo en temáticas sociales y la problemática humana cotidiana. Sus canciones van por el camino de la Trova y del Canto Latinoamericano (Mora, 2021).

Por trabajo y formación ha viajado a México, Canadá, Estados Unidos, Colombia, Argentina, Uruguay, Bolivia, Brasil, Centro América y Panamá. En febrero del año 2018, fue elegido "Artista del mes" por la radio Universidad de Costa Rica. Ha cantado junto al argentino Tomás Lipán, los cubanos Karel García y Francisco Brito, los venezolanos Lalo Moreno y René Torres. Los costarricenses Cristian Porras, Natalia Esquivel y Max Goldenberg, los guatemaltecos Fernando López y Tito Medina, los mexicanos Salvador Aviña, Felix Díaz y Darío Parga. La colombiana María Mejía y el grupo Los Guaraguao de Venezuela, entre otros. Ha participado en festivales de Trovadores en México y de Poesía en Guatemala, donde ha recibido reconocimientos por su trayectoria.

Junto a otros trovadores guatemaltecos, organizó recientemente, el primer Festival Xela Trova 2020. Es además, Agrónomo, Licenciado en economía, Máster en Administración de Empresas, tiene el Postgrado de Experto en Dinámica de Sistemas. Actualmente estudia el Doctorado Pensamiento Complejo, en Multiversidad Mundo Real Edgar Morin Una Visión Integradora, en Sonora, México.

Volumen 4 | Número 2 |Julio - Diciembre 2021 
Ha escrito documentos como resultado de investigaciones y publicaciones en diversos temas. Otto Mora, cree que las canciones son un poderoso medio para incidir en la conducta de los pueblos, por lo que se considera un respetuoso "cantor del Canto Popular" (Mora, 2021).

\section{Estética, belleza y complejidad}

Estética deriva del griego Aisthesis que significa "percibir por los sentidos". Nace a finales del siglo 18, según Maldonado-Castañeda (2021) sin embargo Alejandro Baumgarten (1714-1762), rescató el término clásico para titular su obra "Estética", considerando que la reflexión en torno a lo bello merecía una preocupación especial. Postuló a la estética como una nueva lógica del conocimiento sensible, inferior en ese entonces, por adquirirse a través de los sentidos, al pensar la estética como la "esencia de la percepción de la belleza", que se percibe desde los ojos del observador.

De la percepción de la belleza surge el arte, que da origen al criterio y al concepto. Entonces, la belleza es un asunto, que depende del observador. Así como observamos la belleza de la naturaleza, la belleza humana, la belleza misma de la ciencia, trasciende la percepción a la belleza del arte como expresión de la existencia humana; con una finalidad estética, un aspecto de la realidad o un sentimiento en formas bellas, valiéndose de la imagen o del sonido a través de la música.

Como expresa Najmanovic (2005) es preciso comprender que la percepción no es un proceso mecánico u óptico, no somos una tabula rasa en la que se imprimen imágenes, ni espejos que la reflejan. La percepción es una actividad formativa, productiva, poética, no un proceso pasivo; es emoción y sentimiento. Hablar de arte integra la música como una manifestación que proporciona una experiencia estética que motiva la percepción individual, la creatividad, estimula los sentimientos, los pensamientos y las ideas.

La valoración estética también puede definirse por el subjetivismo presente en la belleza de las obras, debido a que la música como todo arte, es una tendencia que refleja la identidad tanto del autor como del receptor, quienes terminan interactuando gracias a los aspectos personales de tipo emocional, lo cual permite descubrir la estética de la obra.

Entre los elementos estéticos musicales están la armonía y la emotividad. Los elementos están inmersos en la estética y las relaciones entre complejidad y estética, que conocen de diversidad, de transformaciones, de emergencia, de impredecibilidad y de autoorganización. No obstante, no se puede dejar de mencionar la creatividad como elemento fundamental en la música, como afirman González Díaz y colaboradores (2020) "... surge la creatividad y la inspiración" en el preciso momento de sentir la música.

Sin embargo los elementos que se entraman en la música y que producen diversas emociones al cantante y a los que escuchan la música, merece que se reflexione desde la dialógica del pensamiento creativo ciencia y arte, estas dimensiones suceden de los campos de conocimientos convergentes, mediante la racionalidad creativa se gestan las inéditas letras poéticas artísticas que se transforman en estética a través de la expresión artística.

Volumen 4 | Número 2 Julio-Diciembre 2021 
Sin embargo, la virtualidad también está relacionada a la complejidad porque a través de la cibernética de segundo orden como lo afirma Villela Cervantes (2018) la disertación académico-musical se realizó con el uso de la tecnología y las redes informáticas de comunicación que generaron de alguna forma ondas cuánticas a través de la conexión que facilitó la plataforma Zoom, las computadoras, el teléfono y muchas otras formas de intercomunicación, llegando a la reflexión que el universo como red incluyente es un entramado relacional.

No estar en presencialidad física, no significa que se deje sentir emociones, como lo afirma Najmanovich (2008) aunque estemos lejos de las personas no podemos de dejar de sentir emociones, de sufrimiento y también de gozo, desde emisión de la voz, del canto y la performance poética del canto.

\section{La velada académico-musical}

Las actividades universitarias suelen ser solemnes y protocolarias. Esa no debe ser la norma pues se obvia el sentido lúdico de lo emocional que es esencial en las Ciencias de la Complejidad. El recital incluyó en primer término la vocalización e interpretación con guitarra, de diversas melodías, en clave de trova. Interpretaciones como Atardecer, Elemental, Luna de Xelajú, Exilio, Unicornio Azul, entre otras.

En seguida, de acuerdo con los objetivos del evento, el trovador disertó sobre la complejidad de la estética de la música y de la belleza de la trova. Expuso que la música tiene tres elementos: melodía, armonía y ritmo. La melodía es la combinación de los acordes, lo que le da identidad a la obra musical. Ningún tema musical tiene una melodía igual a la de otro. La armonía es la balanceada secuencia de notas musicales que impresionan y provocan emoción al ser humano, como a los animales y de acuerdo a algunos estudios científicos, también afecta a las plantas, ¿Quién no ha notado que sus plantas prosperan cuando se exponen a la música?

Por último, el ritmo; un elemento que en su momento se constituyó en el embrión de la música, partiendo del pulso cardiaco; hablamos del corazón el órgano donde se asegura residen las emociones, entre ellas, sobre todo, esa experiencia impactante, ineludible y no pocas veces traumática; y que por lo tanto marca al ser humano, desde pocas semanas del desarrollo fetal.

De esa manera, la integración de los tres elementos hacen de la música un fenómeno complejo por la relación de sus elementos. Mora aseveró que la trova es poema con música que está vinculada al pensamiento sistémico, ya que nos plantea el concepto de propiedades emergentes de los sistemas como el calor, la sinergia y la buena vibra; asegurando que la música es una propiedad emergente del sistema que la produce.

\section{Conclusión}

El sonido puede ser música o ruido. Puede agradar (aunque no siempre) y el otro puede lastimar, son fenómenos físicos, que implican movimiento, como cuando un objeto golpea a otro. El soplo del viento es un movimiento oscilante que produce ruido, a través de ondas sonoras; no obstante, la música es un fenómeno mucho más complejo que el ruido, porque combina varios elementos. 
Najmanovich, D. (2008). Mirar con nuevos ojos, nuevos paradigmas en la ciencia y pensamiento complejo. Editorial Biblos. Buenos Aires Argentina. pensamientos y las ideas. La valoración estética se define por el subjetivismo presente en la belleza de las obras, debido a que la música como todo arte, es una tendencia que refleja la identidad tanto del autor como del receptor, quienes terminan interactuando gracias a los aspectos personales de tipo emocional, lo cual permite descubrir la estética de la obra.

\section{Referencias}

González Díaz, O. A. ., Tzoc, J. ., López, J. M. . y Argueta Ramos , S. T. (2020). La naturaleza de la creatividad. Revista Vida, Una Mirada Compleja, 2(1), 53-67. https://doi.org/10.36314/revistavida.v2i1.8

Maldonado-Castañeda, C. E. (2021) Estética y complejidad: elementos para un estado crítico del arte. Creación Arte y Ciencia. Bogotá Colombia. https://www.academia.edu/44819881/Est\%C3\%A9tica_y_ Complejidad_Elementos_para_un_estado_cr\%C3\%ADtico_del_arte

Mora, O. (2021). Disertación Académico-musical "La Estética de la música y la belleza de la trova". Doctorado en Investigación en Educación. Universidad de San Carlos de Guatemala.

Najmanovich, D. (2005). Estética del pensamiento complejo. Andamios, 1(2), 19-42.http://www. scielo.org.mx/scielo.php?script=sci_arttext\&pid=S1870-00632005000300002\&ln$g=e s \& t$ tng=es
Copyright (c) (2021) Claudia Esmeralda Villela Cervantes

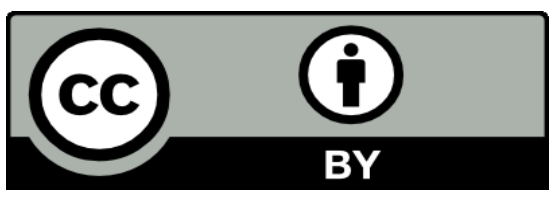

Este texto está protegido por una licencia Creative Commons 4.0.

Es libre para compartir, copiar y redistribuir el material en cualquier medio o formato y adaptar el documento, remezclar, transformar y crear a partir del material para cualquier propósito, incluso comercialmente, siempre que cumpla la condición de atribución: debe reconocer el crédito de una obra de manera adecuada, proporcionar un enlace a la licencia, e indicar si se han realizado cambios. Puede hacerlo en cualquier forma razonable, pero no de forma tal que sugiera que tiene el apoyo del licenciante o lo recibe por el uso que hace. 